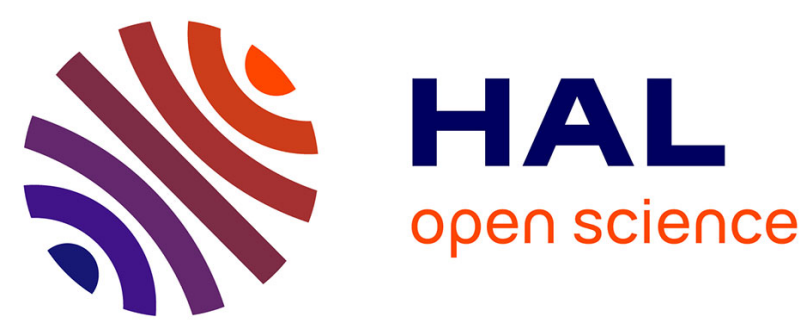

\title{
Supramolecular assemblies of Al3 + complexes with vitamin D3 (cholecalciferol) and phenothiazine. Encapsulation and complexation studies in $\beta$-cyclodextrin
}

D. F Soares, M. D Noseda, J. Felcman, Mustayeen A. Khan, G. Bouet, A. L Ramalho Mercê

\section{To cite this version:}

D. F Soares, M. D Noseda, J. Felcman, Mustayeen A. Khan, G. Bouet, et al.. Supramolecular assemblies of $\mathrm{Al} 3+$ complexes with vitamin D3 (cholecalciferol) and phenothiazine. Encapsulation and complexation studies in $\beta$-cyclodextrin. Journal of Inclusion Phenomena and Macrocyclic Chemistry, 2013, 75 (1-2), pp.137-145. 10.1007/s10847-012-0154-4 . hal-03258131

\section{HAL Id: hal-03258131 \\ https://univ-angers.hal.science/hal-03258131}

Submitted on 15 Jun 2021

HAL is a multi-disciplinary open access archive for the deposit and dissemination of scientific research documents, whether they are published or not. The documents may come from teaching and research institutions in France or abroad, or from public or private research centers.
L'archive ouverte pluridisciplinaire HAL, est destinée au dépôt et à la diffusion de documents scientifiques de niveau recherche, publiés ou non, émanant des établissements d'enseignement et de recherche français ou étrangers, des laboratoires publics ou privés. 


\section{Supramolecular assemblies of $\mathrm{Al}^{3+}$}

complexes with vitamin $\mathrm{D}_{3}$ (cholecalciferol) and phenothiazine. Encapsulation and complexation studies in $\beta$-cyclodextrin

\section{F. Soares, M. D. Noseda, J. Felcman, M. A. Khan, G. Bouet \& A. L. Ramalho Mercê}

Journal of Inclusion Phenomena and Macrocyclic Chemistry and Macrocyclic Chemistry

ISSN 0923-0750

$\mathrm{J}$ Incl Phenom Macrocycl Chem DOI 10.1007/s10847-012-0154-4

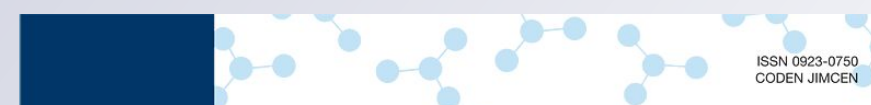

Journal of Inclusion Phenomena and Macrocyclic Chemistry Volume 51, Nos. 1-2, February 2005

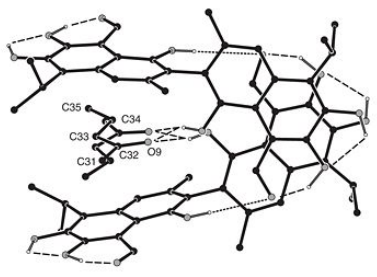

From M.K. Dowd and E.D. Stevens; see p. 70

Springer 
Your article is protected by copyright and all rights are held exclusively by Springer Science+Business Media B.V.. This e-offprint is for personal use only and shall not be selfarchived in electronic repositories. If you wish to self-archive your work, please use the accepted author's version for posting to your own website or your institution's repository. You may further deposit the accepted author's version on a funder's repository at a funder's request, provided it is not made publicly available until 12 months after publication. 


\title{
Supramolecular assemblies of $\mathrm{Al}^{3+}$ complexes with vitamin $\mathrm{D}_{3}$ (cholecalciferol) and phenothiazine. Encapsulation and complexation studies in $\beta$-cyclodextrin
}

\author{
D. F. Soares $\cdot$ M. D. Noseda $\cdot$ J. Felcman $\cdot$ \\ M. A. Khan · G. Bouet • A. L. Ramalho Mercê
}

Received: 13 February 2012/ Accepted: 21 March 2012

(C) Springer Science+Business Media B.V. 2012

\begin{abstract}
Ternary assemblies of $\beta$-cyclodextrin with cholecalciferol (or vitamin $\mathrm{D}_{3}$ ) or phenothiazine and $\mathrm{Al}^{3+}$ ions were studied. The stability constants of aluminium binary complexes with cholecalciferol or phenothiazine and of ternary assemblies ( $\beta$-cyclodextrin, cholecalciferol or phenothiazine and $\mathrm{Al}^{3+}$ ) were determined using potentiometric titrations at $25^{\circ} \mathrm{C}(I=0.100 \mathrm{M})$. The ${ }^{13} \mathrm{C}$ NMR spectra of the supramolecular structures in the solid state showed that ternary supramolecular structures associating $\beta$-cyclodextrin, cholecalciferol or phenothiazine and aluminium(III) ions were obtained. Finally, X-ray powder
\end{abstract}

Electronic supplementary material The online version of this article (doi:10.1007/s10847-012-0154-4) contains supplementary material, which is available to authorized users.

D. F. Soares · A. L. Ramalho Mercê

Chemical Equilibrium Laboratory, Chemistry Department, Universidade Federal do Paraná, CP 1908, Curitiba,

PR 81531-990, Brazil

M. D. Noseda

Biochemistry Department, Universidade Federal do Paraná, CP 1908, Curitiba, PR 81531-990, Brazil

\section{J. Felcman}

Chemistry Department, Pontifícia Universidade Católica do Rio de Janeiro, Rua Marquês de São Vicente, 225, Gávea, Rio de Janeiro, RJ 22453-900, Brazil

\section{A. Khan}

Chimie de Coordination, UFR Sciences Pharmaceutiques et Ingénierie de la Santé, Université d'Angers, 16 Boulevard Daviers, 49045 Angers Cedex, France

\section{G. Bouet $(\bowtie)$}

Laboratoire SONAS EA 921, SFR QUASAV 4207, UFR

Sciences Pharmaceutiques et Ingénierie de la Santé, Université d'Angers, 16 Boulevard Daviers, 49045 Angers Cedex, France e-mail: gilles.bouet@univ-angers.fr diffraction patterns showed that the ternary assemblies with phenothiazine are channel type inclusion complexes.

Keywords Ternary supramolecular assemblies . $\beta$-Cyclodextrin · Vitamin D P Phenothiazine · Aluminium

\section{Introduction}

Supramolecular binary or ternary assemblies are often used for various purposes. When organic compounds, like drugs, or inorganic cations are encapsulated in cyclodextrins as hosts, they may display new properties. Among cyclodextrins, $\beta$-cyclodextrins $(\beta$-CD) are the more often used mainly for studies in aqueous medium $[1,2]$. So, $\beta$-CD are very common inclusion materials $[3,4]$ producing prodrugs able to deliver drugs under specific environmental conditions [5]. Modified cyclodextrins lead to inclusion complexes as well [6].

Binary assemblies where an organic substance is incorporated into the cyclodextrin cavity are the more often described and, for instance, there are some papers reporting inclusions complexes of vitamin $\mathrm{D}_{3}$ or cholecalciferol (Vit D) [7]. On the opposite side, there are very few papers describing ternary supramolecular assemblies. Some articles dealt with ternary complexes associating $\beta$-CD, an organic molecule and a metal ion [8-11]. Recently, Marques et al. reported the inclusion of ruthenium(II) complexes in $\beta$-CD [12], while Ding et al. [13] published some ternary association with zinc(II). In this way, we have previously described the formation of ternary assemblies: $\beta$-CD:Vit D:metal ions $\left(\mathrm{Co}^{2+}, \mathrm{Cu}^{2+}, \mathrm{Zn}^{2+}\right)$, in which the molecular ratios were 5:1:1 or 10:1:1, respectively [14].

$\mathrm{Al}(\mathrm{III})$ compounds are involved in human health but they are also suspected in neurological disorders [15]. In 
the mean time, the $\mathrm{Al}^{3+}$ ion could be coordinated by cholecalciferol in ethanol-water medium [16]. In 2008, Dias et al. described ternary assemblies associating cyclodextrin and $\mathrm{Al}(\mathrm{III})$ with catechin or quercetin. Using IR and UV-Vis spectra, ${ }^{1} \mathrm{H}$ and ${ }^{13} \mathrm{C}$ NMR associated with TG and DTA, they concluded to 1:1 complex aluminium to $\beta$-cyclodextrin ratio [17].

Vitamin $\mathrm{B}_{10}$ could be included in $\beta$-CD, leading to $1: 1$ inclusion complex [18]. $\beta$-CD was also used to encapsulate hydrophobic drugs like indomethacin associated with water and ammonia [19, 20]. The complexation of an amphiphilic chiral derivative of phenothiazine (pheno) was described by Guerrero-Martinez et al. [21]. They concluded that the low flexibility of the cyclodextrin could lead to chiral recognition due to the existence of two binding sites on the $\beta$-CD molecules. Methylene blue and phenothiazine could also be included in $\beta$-cyclodextrin using sodium dodecyl sulfate micelles [22].

The aim of the present work was first to obtain prodrugs (using $\beta$-CD inclusion) able to deliver cholecalciferol or phenothiazine when useful. Phenothiazine is also an essential pharmacophore for some drug agents, especially tranquilizer drugs, and also may be a model of a polyaromatic substance, miming degradation products of some phytotoxic fertilizers. In the mean time, it should be efficient to complex aluminum to prevent environment from its contamination. The ternary assembly $\beta$-cyclodextrin, phenothiazine and $\mathrm{Al}^{3+}$ could be useful to extract toxic compounds from intensive agriculture and aluminium at once.

In this paper, we describe some new $\beta$-cyclodextrin ternary assemblies with aluminum(III) and cholecalciferol or phenothiazine. ${ }^{13} \mathrm{C}$ NMR spectra and XRD allowed us to determine the nature of these assemblies in the solid state. Using potentiometric titrations, the values of the binding constants of the various supramolecular binary and ternary assemblies were determined.

\section{Experimental}

\section{Chemicals}

All reagents were analytical grade and were used as received. Aluminium chloride standard solution, potassium chloride and absolute ethanol were Merck (Germany). Cholecalciferol, $\beta$-cyclodextrin hydrate and phenothiazine were Sigma-Aldrich (USA). Nitric acid, potassium hydroxide and potassium hydrogen phthalate were Riedelde-Häen (Germany). KCl was Carlo Erba (Italy), $\mathrm{Na}_{2}$ EDTA was Reagen (Brazil), hexadeuterated dimethyl sulphoxide DMSO-D 6 (99.9 \%) and TMS (sodium-3-trimethylsilylpropionate) were Cambridge Isotope Laboratories, Inc. (USA). $\mathrm{ZnSO}_{4}$ and dithizone were Merck
(Germany). Water used was bidistilled in a quartz bidistillator (Tecnal, Brazil) and deionized in a cationic exchange column and freshly boiled.

Synthesis of the supramolecular assemblies of $\beta$-cyclodextrin

An amount of 0.02 or $0.04 \mathrm{mmol}$ of Vit D or phenothiazine (pheno) were dissolved in absolute EtOH $(25 \mathrm{~mL})$. $0.2 \mathrm{mmol}$ of $\beta$-CD previously dissolved in water $(25 \mathrm{~mL})$ were mixed with magnetic stirring under $\mathrm{N}_{2}$ atmosphere whenever Vit $\mathrm{D}$ were present, for at least $4 \mathrm{~h}$. When the synthesis were made in the presence of $\mathrm{Al}^{3+}$, the same ratios used for the previous reagents were maintained and the metal ion quantity was identical to the quantity of added guest $(0.02$ or $0.04 \mathrm{mmol}$ ) and the $\mathrm{pH}$ set to the $4.5-5.5$ range [14]. The obtained complex assemblies were then $\beta$-CD:pheno: $\mathrm{Al}^{3+}$ or $\beta$-CD:Vit D:Al ${ }^{3+}$ with the following molar ratios: 10:1:1 and 5:1:1 when 0.04 or $0.02 \mathrm{mmol}$ were added of both pheno or Vit $\mathrm{D}$ and $\mathrm{Al}^{3+}$, respectively.

The supramolecular assemblies were dried in a rotary evaporator (Fisatom, Brazil) under vacuum until the solids were completely dried. They were finally stocked in small closed glasses, in a dessiccator.

\section{Potentiometric titrations}

Potentiometric titrations were carried out in triplicate under $\mathrm{N}_{2}$ atmosphere and at constant temperature $25.0 \pm 0.1{ }^{\circ} \mathrm{C}$ (Thermostated bath MQBTC 99-20, Microquímica, Brazil) and constant ionic strength $(I=0.100 \mathrm{M}, \mathrm{KCl})$. The calculations of millimols of reagents and the binding constants were done with the help of Hyperquad program [23] and the species distribution diagrams were drawn with HYSS program [24]. All information required for the proper input for the program were provided or calculated, as the concentration of all reagents, the hydrolysis constants for $\mathrm{Al}^{3+}$ taken from literature [25] and concentration of $\mathrm{KOH}$ (potassium hydrogen phthalate standardization with phenolphthalein) and the $\mathrm{Al}^{3+}$ solution acid content, by Gran's Plot [26, 27]. The metal ion was determined by complexometric back titration with $\mathrm{ZnSO}_{4}$ and dithizone as indicator (standardized final concentrations of $\mathrm{AlCl}_{3}$ solution were $\left[\mathrm{H}^{+}\right]=0.1334$ and $\left[\mathrm{Al}^{3+}\right]=$ $0.01045 \mathrm{M}$ ). An Orion $\mathrm{pH}$ meter (model 420A, USA) with $\mathrm{H}^{+}$ and $\mathrm{Ag} / \mathrm{AgCl}$ (Orion, Switzerland) reference electrodes was calibrated to differences no higher than $0.005 \mathrm{pH}$ units in acidic region and $0.015 \mathrm{pH}$ units in basic region. $\mathrm{KCl}$ was the supporting electrolyte used to maintain the ionic strength of all system at $0.100 \mathrm{M}$, with $\mathrm{p} K_{\mathrm{w}}=13.78$ for the aqueous conditions and 14.71 for $70 \% \mathrm{v} / \mathrm{v}$ ethanol/water solutions for the experiments done with Vit D [9]. A Sigma Techware (USA) piston burette was used to deliver the titrant, free $\mathrm{CO}_{2}$ standard $\mathrm{KOH}(\sim 0.1 \mathrm{M}, 0.02 \pm 0.01 \mathrm{~mL})$. 
${ }^{13} \mathrm{C}$ NMR experiments

Proton decoupled ${ }^{13} \mathrm{C}$-NMR spectra of binary and ternary synthesized solid complexes $(10 \mathrm{mg})$ were recorded on a Bruker Advance DRX400 spectrometer $(100.61 \mathrm{MHz}$, Germany) on samples in DMSO- $\mathrm{D}_{6}(0.5 \mathrm{~mL})$ solution in quartz tubes for $2 \mathrm{~h}$. Samples $\left(5 \mathrm{mg} \mathrm{mL}{ }^{-1}\right)$ were analyzed using a $5 \mathrm{~mm}$ inverse probe at $30^{\circ} \mathrm{C}$. The pulse sequence was used with a delay (D1) and acquisition time (AQ) of 0.10 and $0.59 \mathrm{~s}$ respectively, using a spectral width of $31.0 \mathrm{kHz}$, $32 \mathrm{~K}$ data points, $90^{\circ}$ pulse $(7.1 \mu \mathrm{s})$, and $8,000-10,000$ scans. The chemical shifts ( $\mathrm{ppm}$ ) were measured relative to an internal TMS standard set at $0.0 \mathrm{ppm}$.

X-ray diffraction analysis

The solid complexes used in ${ }^{13} \mathrm{C}$ NMR spectra were analyzed in a glass holder by X-ray diffraction (XRD) employing a Shimadzu diffractometer XRD6000 (Japan), with a $\mathrm{CuK} \alpha$ monochromator $\left(1.5418 \AA\right.$ ), in the $10-80^{\circ} 2 \theta$ range, with a $2^{\circ} \min ^{-1}$ sweep rate.

\section{Results and discussion}

The structure of $\beta$-CD is given in Fig. 1 while the chemical structures of cholecalciferol and phenothiazine are shown in Fig. 2.

\section{Equilibrium constants}

The potentiometric $\mathrm{pH}$ profiles of $\beta$-CD, pheno and Vit $\mathrm{D}$ on one hand and $\beta$-CD:pheno and $\beta$-CD:Vit $\mathrm{D}$ on the other hand, are shown in Figs. 3 and 4. These curves show the changes in the different ligand to metal ratios studied profiles for both binary and ternary systems, in the presence of $\mathrm{Al}^{3+}$ ions.

Figure 3 shows the titration profiles of pheno alone and in the presence of $\mathrm{Al}^{3+}$ (with increasing ligand to metal ratio $1: 1,2: 1$ and $3: 1$ ). Figure 4 depicts the $\mathrm{pH}$ profiles of supramolecular assembly $\beta$-CD:pheno and $\beta$-CD:pheno with $\mathrm{Al}^{3+}$ (ligand to metal ratios of 1:1 and 2:1). In Fig. 5, are drawn the experimental and the calculated $\mathrm{pH}$ profiles of the supramolecular assembly $\beta$-CD:Vit $\mathrm{D}$ in the presence of $\mathrm{Al}^{3+}$ in ligand to metal ratios of 5:1:1 and we note a good fit between the two curves, owing us to validate the model used in our calculations. In all potentiometric profiles, the inorganic acid added to the $\mathrm{Al}^{3+}$ solution was previously discounted.

These $\mathrm{pH}$ data were used to determine the complexed species present in the system using calculations performed with Hyperquad program [23]. The logarithms of the binding constants, calculated as previously described

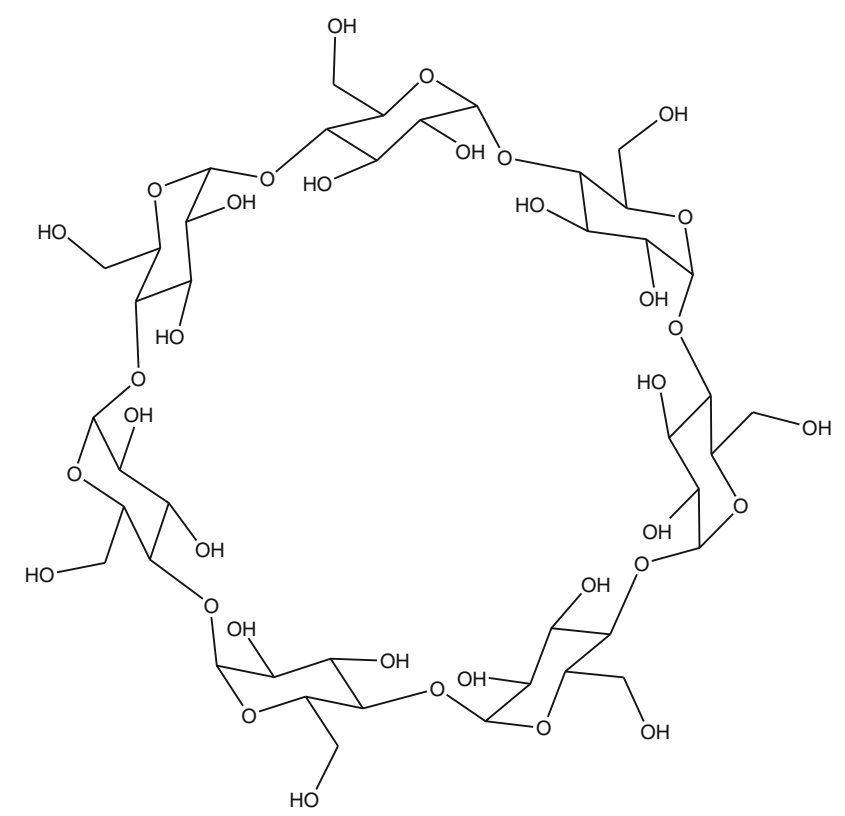

Fig. 1 Molecular structure of $\beta$-CD

$[16,28]$, in all present systems are listed in Table 1 . The simulation procedure was made in all experiments and calculations but it was only shown in the ternary systems (Fig. 5) in order to validate the binding constants calculated. All calculated values were done for species with a percentage higher than $10 \%$ in the equilibrium, assuming that the total metal concentration is $100 \%$.

The $\log \beta_{1}$ for binary systems $\beta$-CD:Al ${ }^{3+}$, pheno: $\mathrm{Al}^{3+}$ are 14.48 and 10.02 respectively, while its value is 12.4 for Vit D: $\mathrm{Al}^{3+}[16]$. Looking at the logarithmic values for the ternary systems (Table 1), we remark that high values are observed. Lower values were observed in similar supramolecular complexes combining $\beta$-CD, copper(II) and functionalized adamantyl ethylene diamine [29]. Our results are explained by the fact that the supramolecular assembly binds the metal ion in a conjugated way, using all possible basic centers (electrons pair donors) in both host $\beta$-CD and guest ligands (pheno or Vit D).

The species distribution curves of the binary and ternary systems (not shown) indicated that at least one complex species was present, with a minimal percentage of $50 \%$ in the 5-8 $\mathrm{pH}$ range. However, there was a variation in the formation of complexed species depending upon the ligand studied. For physiological pH value (7.4) there was the presence of, at least, one complexed species in all studied systems.

\section{${ }^{13} \mathrm{C}$ NMR spectra}

The carbon numbering scheme for $\beta$-cyclodextrin used in this paper was previously proposed by several authors $[14,30-32]$, the numbering scheme for pheno was given by 
Fig. 2 Chemical structures of vitamin $\mathrm{D}_{3}$ (a) and phenothiazine (b) with carbon numbering schemes

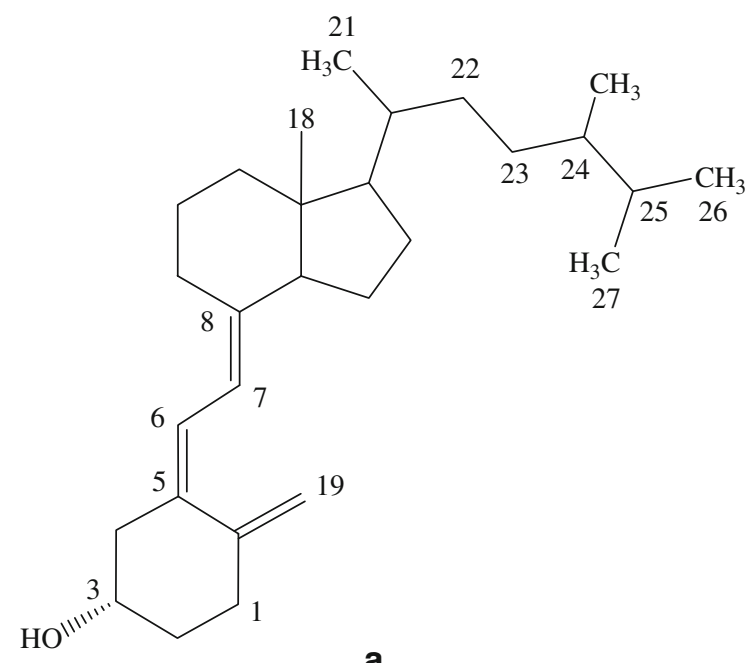

a<smiles>c1ccc2c(c1)Nc1ccccc1S2</smiles>

b

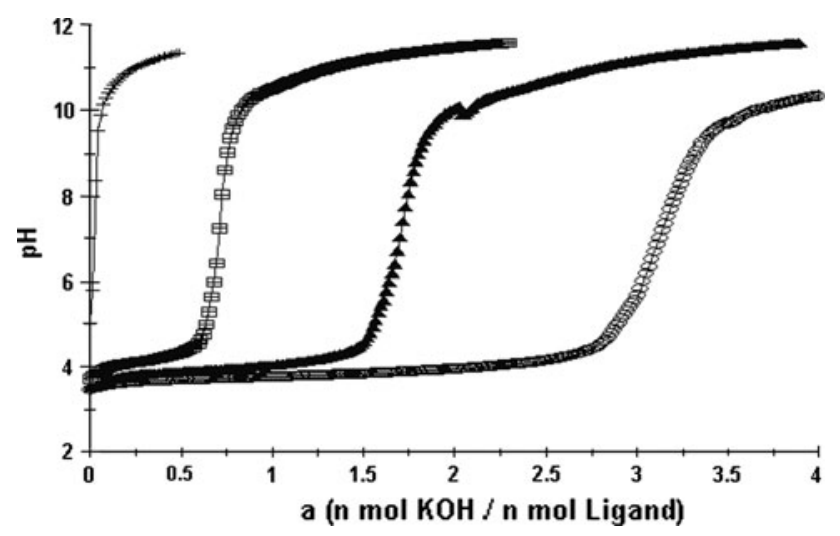

Fig. 3 Potentiometric pH profile $\left(25.0{ }^{\circ} \mathrm{C}, I=0.100 \mathrm{M}, \mathrm{KCl}\right)$ of pheno (black line), pheno:Al 1:1 ratio (circles), 2:1 ratio (triangles) and 3:1 ratio (squares)

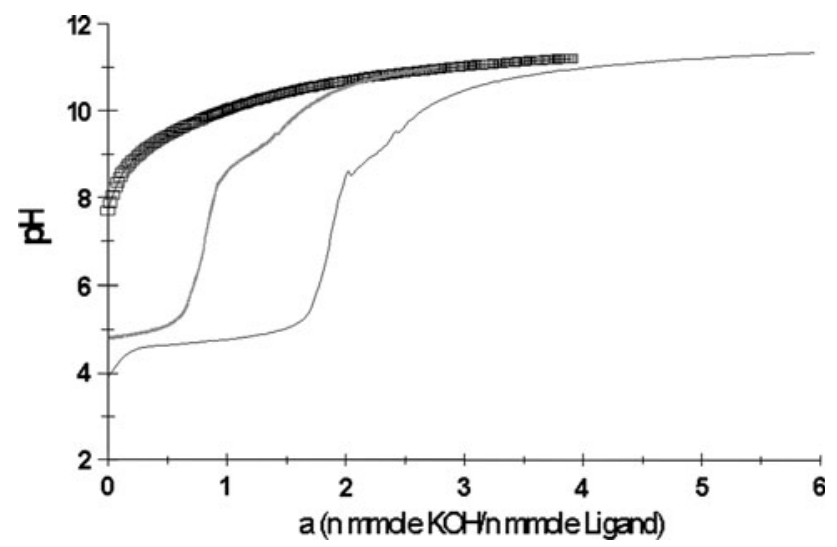

Fig. 4 Potentiometric pH profile $\left(\mathrm{T}=25.0^{\circ} \mathrm{C}, I=0.100 \mathrm{M}, \mathrm{KCl}\right)$ of $\beta$-CD:pheno alone (squares), and with $\mathrm{Al}^{3+}$ in $1: 1$ ratio (black line) and in 2:1 ratio (grey line)

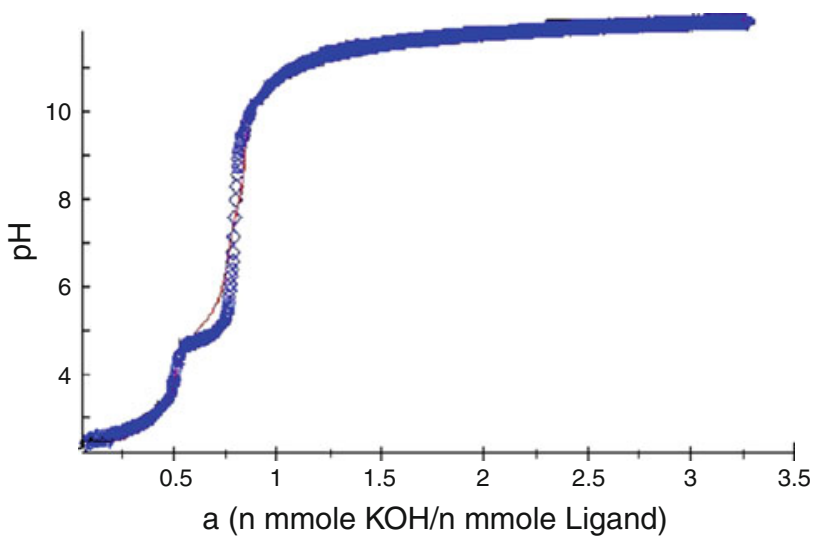

Fig. 5 Experimental (diamond) and calculated (line) potentiometric $\mathrm{pH}$ data of supramolecular assembly $\beta$-CD:Vit $\mathrm{D}$ with $\mathrm{Al}^{3+}$ in $5: 1: 1$ ratio $\left(25.0^{\circ} \mathrm{C}, I=0.100 \mathrm{M}, \mathrm{KCl}\right)$

Palafox [33]. The chemical shifts of the complexed species are listed in Tables 2, 3 and 4 and experimental spectra are shown in Figs. 6, 7 and 8.

In our experiments, the ${ }^{13} \mathrm{C}$ NMR chemical shifts for $\beta$-CD in DMSO- $_{6}$ are (Fig. 6): $\mathrm{C} 1=103.356, \mathrm{C} 2=$ $73.827, \mathrm{C} 3=74.469, \mathrm{C} 4=83.003, \mathrm{C} 5=73.456$ and $\mathrm{C} 6=$ $61.384 \mathrm{ppm}$ [34]. The chemical shifts for ${ }^{13} \mathrm{C}$ NMR of vitamin $\mathrm{D}_{3}$ were previously reported $[14,35,36]$. The ${ }^{13} \mathrm{C}$ chemical shifts for pheno are $\mathrm{C} 2$ and $\mathrm{C} 11=115.953, \mathrm{C} 6$ and $\mathrm{C} 9=$ $117.884, \mathrm{C} 4$ and $\mathrm{C} 13=123.252, \mathrm{C} 5$ and $\mathrm{C} 14=127.718, \mathrm{C} 3$ and $\mathrm{C} 12=129.012 \mathrm{ppm}$ and $\mathrm{C} 1$ and $\mathrm{C} 10$ at $143.620 \mathrm{ppm}$ and these values agree with those reported in the literature [33, 37, 38].

We have calculated the difference between the chemical shifts of $\beta$-CD alone and for the same carbon atom in binary and ternary systems (Tables $2,3,4$ ). In binary 
Table 1 Logarithms of the binding constants for the binary and ternary systems, $\mathrm{T}=25.0{ }^{\circ} \mathrm{C}$ and $I=0.100 \mathrm{M}(\mathrm{KCl})$

\begin{tabular}{|c|c|c|c|c|}
\hline Equilibrium & $\beta-\mathrm{CD}+\mathrm{Al}^{3+}$ & pheno $+\mathrm{Al}^{3+}$ & $\beta$-CD:pheno $+\mathrm{Al}^{3+}$ & $\beta$-CD:Vit $\mathrm{D}+\mathrm{Al}^{3+}$ \\
\hline$[\mathrm{ML}] /[\mathrm{M}] \cdot[\mathrm{L}]$ & $14.48 \pm 0.07$ & $10.02 \pm 0.03$ & $19.6 \pm 0.1$ & $31.3 \pm 0.3$ \\
\hline$\left[\mathrm{ML}_{2}\right] /[\mathrm{ML}] \cdot[\mathrm{L}]$ & $14.1 \pm 0.4$ & n.d. & $18.5 \pm 0.5$ & $20.3 \pm 0.5$ \\
\hline$[\mathrm{MLOH}] /[\mathrm{M}] \cdot[\mathrm{L}] \cdot[\mathrm{OH}]$ & n.d. & n.d. & $16.9 \pm 0.1$ & n.d. \\
\hline$\left[\mathrm{M}_{2} \mathrm{LH}\right] /[\mathrm{M}]^{2} \cdot[\mathrm{L}] \cdot[\mathrm{H}]$ & n.d. & n.d. & $25.7 \pm 0.2$ & n.d. \\
\hline
\end{tabular}

Table 2 Chemical shifts of the ${ }^{13} \mathrm{C}$ NMR in DMSO-D 6 of $\beta$-CD and $\mathrm{Al}^{3+}$ and the differences $\delta=\delta(\beta$-CD)- $\delta(\beta-\mathrm{CD}+\mathrm{Al})$

\begin{tabular}{lllrrrr}
\hline & $\mathrm{C}(1)$ & $\mathrm{C}(2)$ & $\mathrm{C}(3)$ & $\mathrm{C}(4)$ & $\mathrm{C}(5)$ & $\mathrm{C}(6)$ \\
\hline$\beta$-CD & 103.356 & 73.827 & 74.469 & 83.003 & 73.456 & 61.384 \\
$\beta$-CD + Al (5:1) & 103.271 & 73.762 & 74.388 & 82.890 & 73.378 & 61.275 \\
$\beta$-CD + Al (10:1) & 103.300 & 73.783 & 74.417 & 82.919 & 73.405 & 61.303 \\
$\Delta \delta(1: 5)$ & 0.085 & 0.065 & 0.081 & 0.113 & 0.078 & 0.109 \\
$\Delta \delta(1: 10)$ & 0.056 & 0.044 & 0.052 & 0.084 & 0.051 \\
\hline
\end{tabular}

Table $3{ }^{13} \mathrm{C}$ NMR chemical shifts of $\beta$-CD, and the supramolecular assembly $\beta$-CD:pheno in the absence and in the presence of $\mathrm{Al}^{3+}$, ligands to metal ratios of 5:1:1 and 10:1:1

\begin{tabular}{|c|c|c|c|c|c|c|}
\hline & $\mathrm{C}(1)$ & $\mathrm{C}(2)$ & $\mathrm{C}(3)$ & $\mathrm{C}(4)$ & $\mathrm{C}(5)$ & $\mathrm{C}(6)$ \\
\hline $\mathrm{a}-\beta-\mathrm{CD}$ & 103.356 & 73.827 & 74.469 & 83.003 & 73.456 & 61.384 \\
\hline b- $\beta$-CD:pheno(5:1) & 103.354 & 73.832 & 74.451 & 83.068 & 73.449 & 61.378 \\
\hline c- $\beta$-CD:pheno:Al (5:1:1) & 103.369 & 73.826 & 74.479 & 82.967 & 73.459 & 61.354 \\
\hline $\mathrm{d}-\beta-\mathrm{CD}:$ pheno(10:1) & 103.316 & 73.799 & 74.417 & 83.008 & 73.413 & 61.338 \\
\hline e- $\beta$-CD:pheno:Al (10:1:1) & 103.391 & 73.844 & 74.502 & 82.992 & 73.482 & 61.385 \\
\hline$\Delta \delta(\mathrm{a}-\mathrm{b})$ & 0.002 & -0.005 & 0.018 & -0.065 & 0.007 & 0.006 \\
\hline$\Delta \delta(\mathrm{b}-\mathrm{c})$ & -0.015 & 0.006 & -0.028 & 0.101 & -0.010 & 0.024 \\
\hline$\Delta \delta(\mathrm{a}-\mathrm{d})$ & 0.040 & 0.028 & 0.052 & -0.005 & 0.043 & 0.046 \\
\hline$\Delta \delta(\mathrm{d}-\mathrm{e})$ & -0.075 & -0.045 & -0.085 & 0.016 & -0.069 & -0.047 \\
\hline
\end{tabular}

Table $4{ }^{13} \mathrm{C}$ NMR chemical shifts of $\beta$-CD and the supramolecular assembly $\beta$-CD:Vit D and with $\mathrm{Al}^{3+}, \beta$-CD:Vit D:Al, in ligands to metal ratios of 5:1:1 and 10:1:1

\begin{tabular}{|c|c|c|c|c|c|c|}
\hline & $\mathrm{C}(1)$ & $\mathrm{C}(2)$ & $\mathrm{C}(3)$ & $\mathrm{C}(4)$ & $\mathrm{C}(5)$ & $\mathrm{C}(6)$ \\
\hline $\mathrm{a}-\beta-\mathrm{CD}$ & 103.356 & 73.827 & 74.469 & 83.003 & 73.456 & 61.384 \\
\hline b- $\beta$-CD:Vit D 5:1 & 103.379 & 73.851 & 74.477 & 83.049 & 73.469 & 61.383 \\
\hline c- $\beta$-CD:Vit D:Al 5:1:1 & 103.325 & 73.811 & 74.446 & 82.948 & 73.427 & 61.339 \\
\hline $\mathrm{d}-\beta$-CD:Vit D:Al 10:1:1 & 103.335 & 73.817 & 74.445 & 82.974 & 73.435 & 61.340 \\
\hline$\Delta \delta(\mathrm{a}-\mathrm{b})$ & -0.023 & -0.024 & -0.008 & -0.046 & -0.013 & 0.001 \\
\hline$\Delta \delta(\mathrm{a}-\mathrm{c})$ & 0.031 & 0.009 & 0.023 & 0.055 & 0.029 & 0.045 \\
\hline$\Delta \delta(\mathrm{b}-\mathrm{c})$ & 0.054 & 0.040 & 0.031 & 0.101 & 0.042 & 0.044 \\
\hline$\Delta \delta(\mathrm{b}-\mathrm{d})$ & 0.044 & 0.034 & 0.032 & 0.075 & 0.034 & 0.043 \\
\hline
\end{tabular}

$\beta-\mathrm{CD}: \mathrm{Al}^{3+}$, all differences appeared to be positive like in the case of copper binary system [14] and higher for 1:5 system that for 1:10 assembly.

The signal of the $\mathrm{C} 4$ atom is shifted in the $\beta$-CD:Al binary system and this shift is higher for 1:5 ratio. The calculated $\delta$ for C6 carbon (external hydroxyl) were the highest in binary system $\beta$-CD:Al whatever the molecular ratio. This difference is not observed with pheno or Vit D alone. These results are consistent with a coordination of $\mathrm{Al}^{3+}$ ions through the external hydrophilic wall of $\beta-\mathrm{CD}$ while Vit D or pheno are included in the internal hydrophobic cavity of the cyclodextrin molecule [39]. In the mean time, the shifts of the internal $\mathrm{C} 2$ and $\mathrm{C} 3$ atoms are higher in ternary systems. 


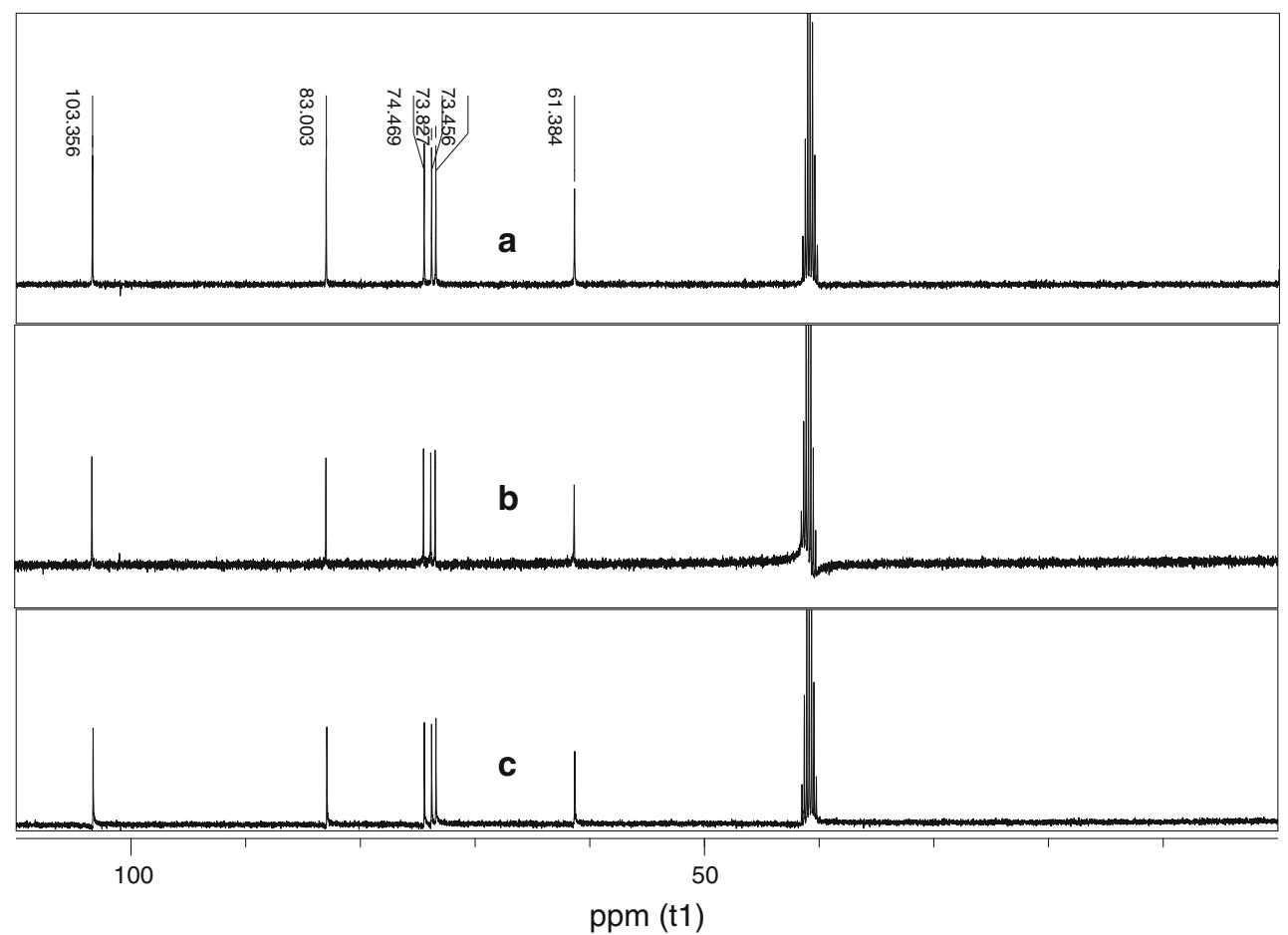

Fig. $6{ }^{13} \mathrm{C}$ NMR spectra: a $\beta$-CD, b $\beta$-CD: $\mathrm{Al}^{3+}, 5: 1$ ligand to metal ratio, c $\beta$-CD:Al ${ }^{3+}, 10: 1$ ratio

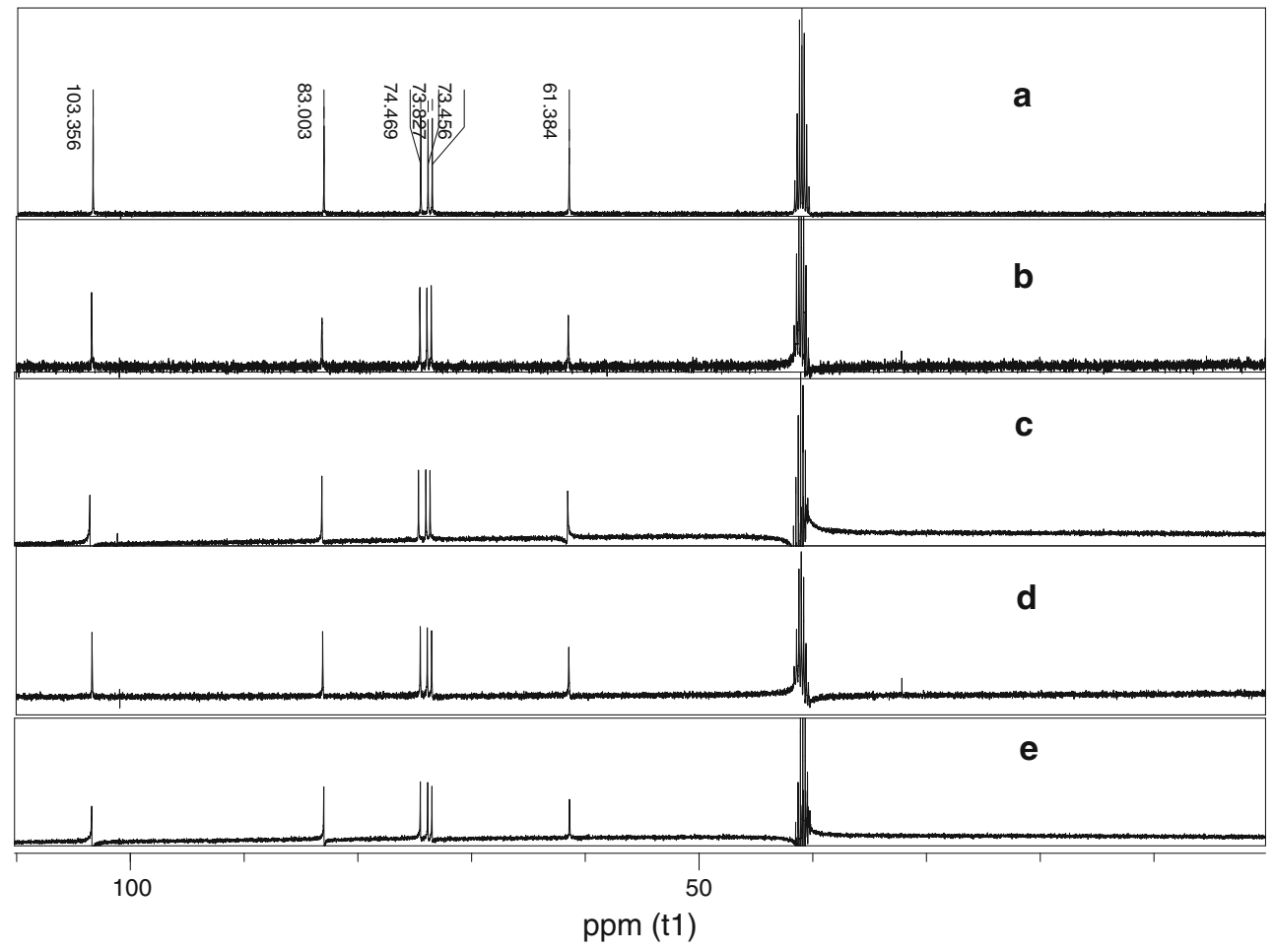

Fig. $7{ }^{13} \mathrm{C}$ NMR spectra: a $\beta$-CD, b $\beta$-CD:pheno, c $\beta$-CD:pheno:Al 5:1:1, d $\beta$-CD:pheno 10:1, e $\beta$-CD:pheno:Al 10:1:1

The shielding effect in the obtained supramolecular structures were higher when the metal ion were not present for $\beta$-CD:Vit $\mathrm{D}$ and on the contrary when the system were with pheno, when in the presence of metal ion, the supramolecular assembly was more shielded. The ligands to metal ratios also showed differences in the chemical shifts 
Fig. $8{ }^{13} \mathrm{C}$ NMR spectra: Vit D alone (grey line) and a $\beta$-CD, b $\beta$-CD:Vit $\mathrm{D}, \mathbf{c} \beta$-CD:Vit D:Al 5:1:1, d $\beta$-CD:Vit D:Al 10:1:1
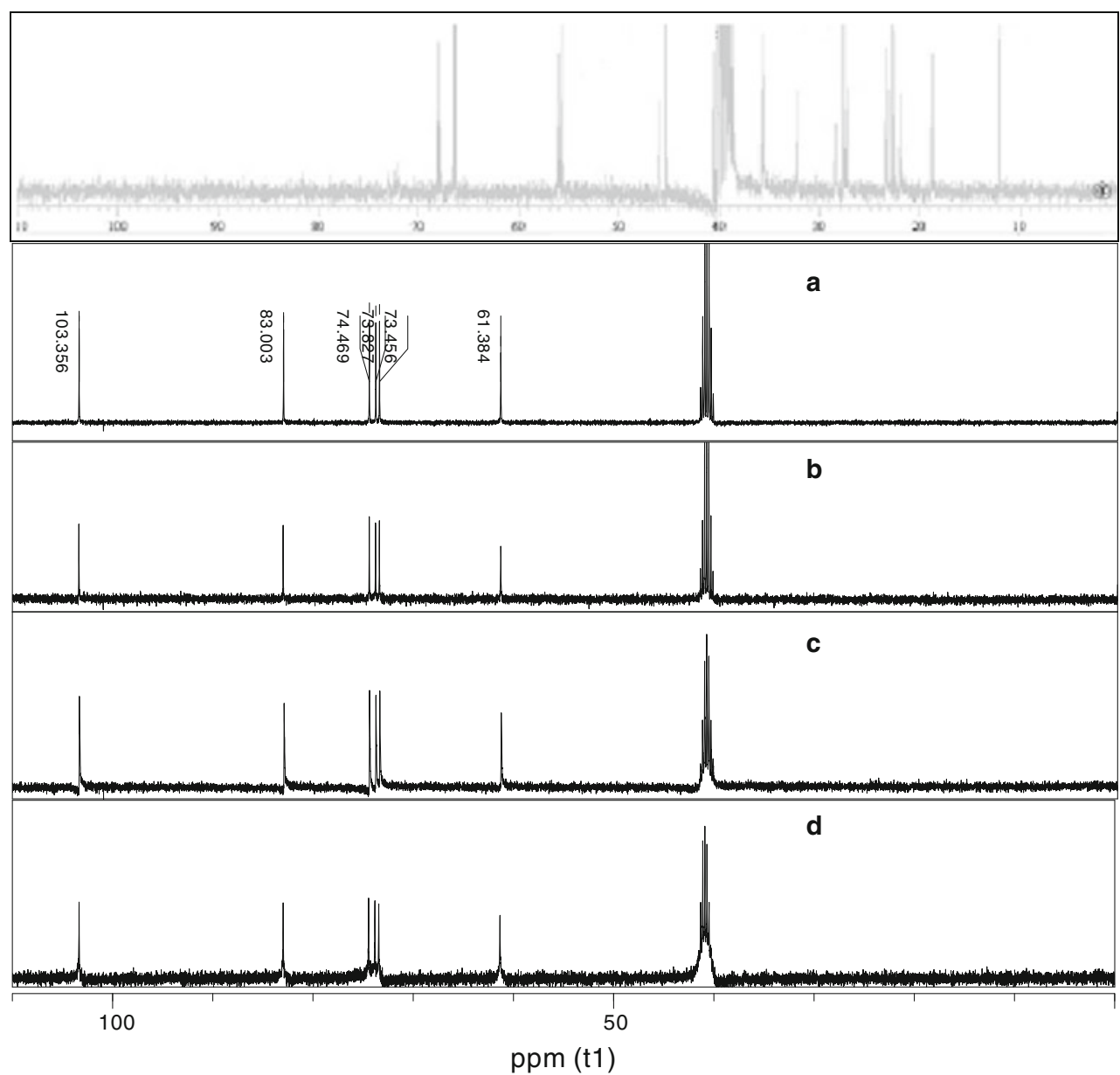

ppm (t1) when compared to one another suggesting different conformations when the quantity of the host and the metal ion were changed.

\section{X-ray powder diffraction}

In Fig. 9, are shown the diffraction patterns of pheno, $\beta$-CD:pheno and $\beta$-CD:pheno:Al.

In the XRD spectra of pheno there are very few lines. In the cases of $\beta$-CD:pheno 5:1 and $\beta$-CD:pheno:Al 5:1:1, respectively we remark the absence of the lines due to pheno when it is encapsulated in $\beta$-CD (Fig. 9). For example, the peak at ca. $2 \theta=28^{\circ}$ disappeared in the case of $\beta$-CD:pheno $5: 1$ but it was present in the case of the ternary assembly $\beta$-CD:pheno:Al 5:1:1. In the cases of $\beta$ CD, $\beta$-CD:Vit D 10:1 and $\beta$-CD:Vit D:Al 10:1:1 (not shown), the same diffraction figures are observed, but the lines for the assemblies are not so sharp and intense than in the case of $\beta$-CD alone. This fact shows that there are no significant changes in the crystallinity of the $\beta$-CD after inclusion even with or without $\mathrm{Al}^{3+}$ in the complexes.

According to Saenger et al. [31] the arrangement is not the same in the supramolecular structures presented.

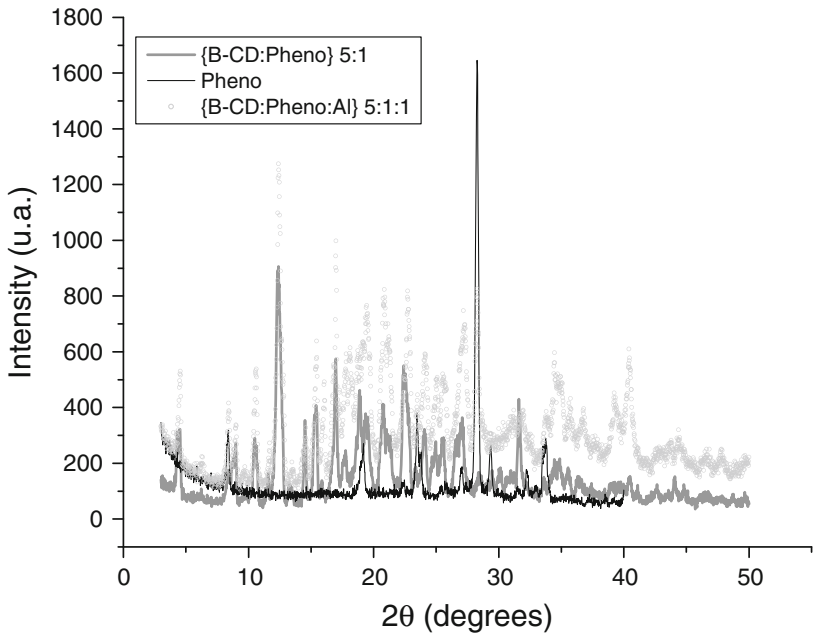

Fig. 9 XDR spectra of pheno, $\beta$-CD:pheno 5:1 and $\beta$-CD:pheno:Al $5: 1: 1$

$\beta$-CD:Vit D inclusion complexes showed, according to previously reported results $[14,40]$, employing XRD that these complexes are channel type inclusion complexes also with $\mathrm{Al}^{3+}$, with a number of diffraction peaks lower than pure $\beta$-CD. On the opposite side, the inclusion complexes 
of pheno, $\beta$-CD formed a cage type structure with or without $\mathrm{Al}^{3+}$ : the lines at $2 \theta=9.5,12.8,13.3$ (less intense in our diagrams) and $18.1^{\circ}$ are typical of a cage type structure [31, 40].

\section{Conclusion}

New supramolecular assemblies of $\beta-\mathrm{CD}$ and phenothiazine or vitamin $\mathrm{D}_{3}$ were synthesized in this work with $\mathrm{Al}^{3+}$ employing previously successfully tested ligands to metal ratios of 10:1:1 and 5:1:1 [14]. They were characterized by studying the solid complexes extracted from aqueous or aqueous ethanol solutions, depending on guest being phenothiazine or vitamin $\mathrm{D}_{3}$, respectively, by ${ }^{13} \mathrm{C} \mathrm{NMR}$. The $\mathrm{X}$-ray diffraction of ternary assemblies showed that they are channel type inclusion complexes. The solution systems were studied by potentiometric titrations and the binding constants were calculated and the speciation according to variation of $\mathrm{pHs}$ were also obtained.

Acknowledgments The authors wish to thank National sponsor agencies of Brazil-CNPq and Capes, and Universidade Federal do Paraná (Brazil).

\section{References}

1. Dodziuk, H.: Cyclodextrins and their Complexes. Wiley-VCH, Weinheim (2006)

2. Song, L.X., Bai, L., Xu, X.M., He, J., Pan, S.Z.: Inclusion complexation, encapsulation interaction and inclusion number in cyclodextrin chemistry. Coord. Chem. Rev. 253, 1276-1284 (2009)

3. Pitha, J.: Enhanced water solubility of vitamins A, D, E, and K by substituted cycloamyloses. Life Sci. 29, 307-311 (1981)

4. Del Valle, E.M.M.: Cyclodextrins and their uses: a review. Process Biochem. 39, 1033-1046 (2004)

5. Loftsson, T.: Cyclodextrins and the biopharmaceutics classification system of drugs. J. Incl. Phenom. Macrocycl Chem. 44, 63-67 (2002)

6. Ding, L., He, J., Huang, L., Lu, R.: Studies on a novel modified $\beta$-cyclodextrin inclusion complex. J. Mol. Struct. 979, 122-127 (2010)

7. Delaurent, C., Siouffi, A.M., Pepe, G.: Cyclodextrin inclusion complexes with vitamin $\mathrm{D}_{3}$ : investigations of the solid complex characterization. Chem. Anal. (Warsaw) 43, 601-616 (1998)

8. Thanabal, V., Omecinsky, D.O., Reily, M.D., Cody, W.L.: The ${ }^{13} \mathrm{C}$ chemical shifts of amino acids in aqueous solution containing organic solvents: application to the secondary structure characterization of peptides in aqueous trifluoroethanol solution. J. Biomol. NMR 4, 47-59 (1994)

9. Zheng, W., Tarr, M.A.: Assessment of ternary iron-cyclodextrin2-naphthol complexes using NMR and fluorescence spectroscopies. Spectrochim. Acta A 65, 1098-1103 (2006)

10. Fernandes, J.A., Braga, S.S., Pillinger, M., Sa Ferreira, R.A., Carlos, L.D., Hazell, A., Ribeiro-Claro, P., Goncalves, I.S.:
$\beta$-Cyclodextrin inclusion of europium(III) tris([beta]-diketonate)bipyridine. Polyhedron 25, 1471-1476 (2006)

11. Cincy, G., Sunny, K., Prakashkumar, B., Tessymol, M.: Synthesis, characterisation and antibacterial applications of water-soluble, silver nanoparticle-encapsulated $\beta$-cyclodextrin. Supramol. Chem. 22, 511-516 (2010)

12. Marques, J., Braga, T.M., Almeida Paz, F.A., Santos, T.M., De Fatima Silva Lopes, M., Braga, S.S.: Cyclodextrins improve the antimicrobial activity of the chloride salt of ruthenium(II) chloro-phenanthroline-trithiacyclononane. Biometals 22, 541-556 (2009)

13. Ding, L., He, J., Fu, J., Zhang, J.: Study on $\beta$-cyclodextrin inclusion of $\mathrm{Zn}(\mathrm{II})$ aromatic complex and its analytical application. Spectrochim. Acta A 75, 604-609 (2010)

14. Mercê, A.L.R., Nicolini, J., Khan, M.A., Bouet, G.: Qualitative study of supramolecular assemblies of [beta]-cyclodextrin and cholecalciferol and the cobalt(II), copper(II) and zinc(II) ions. Carbohydr. Polym. 77, 402-409 (2009)

15. Kawahara, M., Konoba, K., Nagata, T., Sadakane, Y.: Aluminium and human health: its intake, bioavailability and neurotoxicity. Biomed. Res. Trace Elements 18, 211-220 (2007)

16. Mercê, A.L.R., Yano, L.S., Khan, M.A., Thanh, X.D., Bouet, G.: Complexing power of vitamin $\mathrm{D}_{3}$ toward various metals. Potentiometric studies of vitamin $\mathrm{D}_{3}$ complexes with $\mathrm{Al}^{3+}, \mathrm{CD}^{2+}$, $\mathrm{Gd}^{3+}$, and $\mathrm{Pb}^{2+}$ ions in water ethanol solution. J. Sol. Chem. 32, 1075-1085 (2003)

17. Dias, K., Nikolaou, S., De Giovani, W.F.: Synthesis and spectral investigation of $\mathrm{Al}(\mathrm{III})$ catechin/ $\beta$-cyclodextrin and $\mathrm{Al}(\mathrm{III})$ quercetin/ $\beta$-cyclodextrin inclusion compounds. Spectrochim. Acta A 70, 154-161 (2008)

18. Kacso, I., Borodi, G., Farcas, S., Hernanz, A., Bratu, I.: Hostguest system of Vitamin B10 in $\beta$-cyclodextrin: characterization of the interaction in solution and in solid state. J. Incl. Phenom. Macrocycl. Chem. 68, 175-182 (2010)

19. Casella, R., Williams, D.A., Jambhekar, S.S.: Solid-state $\beta$-cyclodextrin complexes containing indomethacin, ammonia and water. I. Formation studies. Int. J. Pharm. 165, 1-14 (1998)

20. Casella, R., Williams, D.A., Jambhekar, S.S.: Solid-state $\beta$-cyclodextrin complexes containing indomethacin, ammonia and water. II. solubility studies. Int. J. Pharm. 165, 15-22 (1998)

21. Guerrero-Martínez, A., Montoro, T., Viñas, M.H., Tardajos, G.: Complexation and chiral drug recognition of an amphiphilic phenothiazine derivative with $\beta$-cyclodextrin. J. Pharm. Sci. 97, 1484-1498 (2008)

22. Guo, X., Xu, H., Guo, R.: Inclusions of methylene blue and phenothiazine by $\beta$-cyclodextrin in sodium dodecyl sulfate micelles. Colloid Polym. Sci. 281, 777-781 (2003)

23. Gans, P., Sabatini, A., Vacca, A.: Investigation of equilibria in solution. determination of equilibrium constants with the HYPERQUAD suite of programs. Talanta 43, 1739-1753 (1996)

24. Alderighi, L., Gans, P., Ienco, A., Peters, D., Sabatini, A., Vacca, A.: Hyperquad simulation and speciation (HySS): a utility program for the investigation of equilibria involving soluble and partially soluble species. Coord. Chem. Rev. 184, 311-318 (1999)

25. Baes, C.F., Mesmer, R.E.: The Hydrolysis of Cations. Wiley, New York (1976)

26. Gran, G.: Determination of the equivalence point in potentiometric titrations. part II. Analyst 77, 661-670 (1952)

27. Martell, A.E., Motekaitis, R.J.: The Determination and Use of Stability Constants. VCH, New York (1992)

28. Mercê, A.L.R., Szpoganicz, B., Dutra, R.C., Khan, M.A., Do Thanh, X., Bouet, G.: Potentiometric study of vitamin D3 complexes with cobalt(II), nickel(II) and copper(II) in water-ethanol medium. J. Inorg. Biochem. 71, 87-91 (1998) 
29. Crespo-Biel, O., Lim, C.W., Ravoo, B.J., Reinhoudt, D.N., Huskens, J.: Expression of a supramolecular complex at a multivalent interface. J. Am. Chem. Soc. 128, 17024-17032 (2006)

30. French, A.D., Murphy, V.G.: The effects of changes in ring geometry on computer models of amylose. Carbohydr. Res. 27, 391-406 (1973)

31. Saenger, W., Jacob, J., Gessler, K., Steiner, T., Hoffmann, D., Sanbe, H., Koizumi, K., Smith, S.M., Takaha, T.: Structures of the common cyclodextrins and their larger analogues-beyond the doughnut. Chem. Rev. 98, 1787-1802 (1998)

32. Lipkowitz, K.B.: Applications of computational chemistry to the study of cyclodextrins. Chem. Rev. 98, 1829-1874 (1998)

33. Palafox, M.A., Gil, M., Núñez, J.L., Tardajos, G.: Study of phenothiazine and $N$-methyl phenothiazine by infrared, raman, ${ }^{1} \mathrm{H}-$, and 13C-NMR spectroscopies. Int. J. Quantum Chem. 89, 147-171 (2002)

34. Jiang, H., Sun, H., Zhang, S., Hua, R., Xu, Y., Jin, S., Gong, H., Li, L.: NMR investigations of inclusion complexes between $\beta$-cyclodextrin and naphthalene/anthraquinone derivatives. J. Incl. Phenom. Macrocycl. 58, 133-138 (2007)

35. Mizhiritskli, M.D., Konstantinovskii, L.E., Vishkautsan, R.: 2D NMR study of solution conformations and complete ${ }^{1} \mathrm{H}$ and ${ }^{13} \mathrm{C}$ chemical shifts assignments of vitamin D metabolites and analogs. Tetrahedron 52, 1239-1252 (1996)

36. Berman, E., Luz, Z., Mazur, Y., Sheves, M.: Conformational analysis of vitamin D and analogs. 1. Carbon-13 and proton nuclear magnetic resonance study. J. Org. Chem. 42, 3325-3330 (1977)

37. Schneider, H.-J., Hacket, F., Rudiger, V., Ikeda, H.: Nmr studies of cyclodextrins and cyclodextrin complexes. Chem. Rev. 98, 1755-1786 (1998)

38. Gaina, L., Csampai, A., Turos, G., Lovasz, T., Zsoldos-Mady, V., Silberg, I.A., Sohar, P.: (E)-3-(2-Alkyl-10H-phenothiazin-3-yl)1-arylprop-2-en-1-ones: preparative, IR, NMR and DFT study on their substituent-dependent reactivity in hydrazinolysis and sonication-assisted oxidation with copper(II)nitrate. Org. Biomol. Chem. 4, 4375-4386 (2006)

39. Ding, L., He, J., Huang, L., Lu, R.: Studies on a novel modified $\beta$-cyclodextrin inclusion complex. J. Mol. Struct. 979, 122-127 (2010)

40. Gao, Y.-A., li, Z.-H., Du, J.-M., Han, B.-X., Li, G.-Z., Hou, W.-G., Shen, D., Zheng, L.-Q., Zhang, G.-Y.: Preparation and characterization of inclusion complexes of $\beta$-cyclodextrin with ionic liquid. Chem. Eur. J. 11, 5875-5880 (2005) 